\title{
Sucrose responsiveness, learning success, and task specialization in ants
}

\author{
Margot Perez, ${ }^{1,2,3}$ Uther Rolland, ${ }^{3}$ Martin Giurfa, ${ }^{1,2,4}$ and Patrizia d'Ettorre ${ }^{3,4}$ \\ ${ }^{1}$ Research Center on Animal Cognition, University of Toulouse, UPS, F-31062 Toulouse Cedex 9, France; ${ }^{2}$ Research Center on Animal \\ Cognition, CNRS, F-31062 Toulouse Cedex 9, France; ${ }^{3}$ Laboratory of Experimental and Comparative Ethology, University Paris 13, \\ Sorbonne Paris Cité, F-93430 Villetaneuse, France
}

\begin{abstract}
Social insects possess remarkable learning capabilities, which are crucial for their ecological success. They also exhibit interindividual differences in responsiveness to environmental stimuli, which underlie task specialization and division of labor. Here we investigated for the first time the relationships between sucrose responsiveness, behavioral specialization, and appetitive olfactory learning in ants, including reproductive castes. We show that castes of the ant Camponotus aethiops differ in their responsiveness to sucrose and in their learning success in olfactory conditioning experiments in which sucrose is used as reward. Olfactory learning was better in foragers than in nurses, in agreement with their higher sucrose responsiveness. Interindividual variation in stimulus responsiveness and in learning may be, therefore, a crucial factor for division of labor in social insects.
\end{abstract}

[Supplemental material is available for this article.]

The capacity to learn and form robust memories about events in the environment is a distinctive trait of social insects (Giurfa 2007, 2013; Avarguès-Weber et al. 2011). It allows them to master changing environments and contributes to their ecological success. Social insects are mainly known for their sophisticated colonial organization, which relies on division of labor-the specialization of individuals in reproduction or in colony maintenance tasks such as brood care, foraging, nest defense, or storage of food resources (Wilson 1971). Task specialization is typically ensured by individuals of different morphological castes and/or ages.

Different models have been proposed to explain division of labor and its relation to colony organization (Beshers and Fewell 2001). The response threshold model, which has been extremely influential in this framework, posits that individuals differ in their sensitivity (and therefore in their responsiveness) to biologically relevant stimuli associated with specific tasks, thus leading to the emergence of division of labor (Robinson 1992; Bonabeau et al. 1996). Differential responsiveness to stimuli that act as positive (e.g., food) or negative (e.g., noxious events) reinforcements results also in variable learning performances, in which individuals learn better about reinforcements to which they are more sensitive (Scheiner et al. 2005).

These behavioral traits have been studied in the honeybee Apis mellifera where individual differences in sucrose responsiveness correlate with individual tendencies to forage either for pollen or nectar (Page et al. 1998; Pankiw and Page 1999; Pankiw et al. 2001; Scheiner et al. 2003). Pollen foragers, for instance, are more responsive to a broad spectrum of sucrose concentrations than nectar foragers, which respond mainly to higher sucrose concentrations (Pankiw and Page 1999). In these experiments, sucrose responsiveness was quantified by stimulating the antennae of restrained bees with increasing sucrose concentrations and determining if proboscis extension reflex (PER) occurred (Pankiw and Page 1999). Interindividual differences are established either via

${ }^{4}$ Corresponding authors

E-mail martin.giurfa@univ-tlse3.fr

E-mail dettorre@leec.univ-paris13.fr

Article is online at http://www.learnmem.org/cgi/doi/10.1101/lm.031427.113. a sucrose response threshold (SRT), i.e., the sucrose concentration at which the response to sucrose differs from that to water (Page et al. 1998), or a sucrose response score (SRS), which is the total number of PER to a series of sucrose concentrations (Pankiw et al. 2001). Sucrose responsiveness not only correlates with the task performed by a bee, but also with its learning success: The lower the SRT (i.e., the higher the SRS), the higher the bee's ability to learn in appetitive conditioning tasks (Scheiner et al. 1999, 2001a,b, 2003; Scheiner and Arnold 2010). These correlations remain so far unique as the interplay between learning, reinforcement responsiveness, and social organization has not been studied in any other social insect.

Ants constitute a remarkable example of eusocial lifestyle (Hölldobler and Wilson 1990). Despite their sophisticated social organization and division of labor, little is known about the determinants of these specializations. Responses to food are flexible and may change among individuals in several ant species (e.g., Josens et al. 1998; Falibene et al. 2009; Schilman 2011). Interindividual differences in sucrose responsiveness were found in immobilized workers of various ant species, which were stimulated with different concentrations of sucrose solution (Falibene and Josens 2012). The possible relationship between these differences, learning success, and behavioral specializations within the colony remains, however, unknown. Yet, relating these variables is possible because, besides the possibility of testing sucrose responsiveness, controlled learning protocols have been recently established for ants (Dupuy et al. 2006; Guerrieri and d'Ettorre 2010; Guerrieri et al. 2011).

Here we provide the first comprehensive study investigating the interplay between learning success, sucrose responsiveness, and task specialization in ants. We focused on the carpenter ant Camponotus aethiops, which feeds to some extent on nectar (mostly from extra-floral nectaries); this species can also be subjected to appetitive olfactory conditioning in harnessing conditions in the laboratory (Guerrieri and d'Ettorre 2010). We determined whether different castes differ in their SRS and analyzed how SRS levels relate to task specialization. We further studied if nurses and foragers differ in appetitive olfactory learning and if these differences relate to their respective SRS levels. 
Nine queenright colonies of C. aethiops were collected at Pompertuzat (Midi-Pyrénées, France, latitude $43.5^{\circ}$, longitude $\left.1.516667^{\circ}\right)$ and kept in the laboratory $\left(24^{\circ} \mathrm{C}, 12\right.$-h light-dark cycle, $60 \%$ humidity), each in two Fluon-coated plastic boxes connected by a plastic hose. One box was provided with plaster floor and covered by cardboard (nest); the other was exposed to light (foraging arena). Colonies were deprived of sucrose $3 \mathrm{wk}$ before the experiments. Mealworms and water were provided ad libitum.

For the experiments, each ant was immobilized by cooling it on ice for $10 \mathrm{~min}$ and then harnessed in a holder (Eppendorf of 0.2 $\mathrm{mL}$ for workers and males, and $1.5 \mathrm{~mL}$ for gynes from which the tip was removed). The ant's head was then passed through the apical hole and strips of adhesive tape were placed between the head and the thorax to prevent body movements except those of the antennae and mouthparts (Supplemental Fig. S1; Guerrieri and $\mathrm{d}^{\prime}$ Ettorre 2010). Ants were then kept in a humid box over $3 \mathrm{~h}$ for recovery and habituation to the harness.

Individual responsiveness scores were quantified via the maxilla-labium extension response (MaLER) (Guerrieri and d'Ettorre 2010) upon stimulation with a series of linear logarithmic ascending concentrations of sucrose solution $(0.1 \%, 0.3 \%, 1 \%, 3 \%, 10 \%$, and 30\% w/w) (Page et al. 1998). Each stimulation lasted 2 sec. Prior to each sucrose stimulation water was delivered to control for sensitization or habituation to increasing sucrose concentration. Groups of 15 ants were tested, one ant at a time, with an interstimulus interval of $7 \mathrm{~min}$. A 10-sec interval was established before and after stimulus presentation to avoid contextual effects. MaLER was scored as 1 when visible, 0 otherwise. Individuals that did not respond to concentrations that were higher than those eliciting prior to responding were discarded $(\sim 7 \%$ of ants in both experiments). Individual sucrose and water responsiveness scores (SRS and WRS, respectively), were quantified as the sum of the ant's response to either stimulus. These scores varied between 0 (no response at any sucrose/water stimulation) and 6 (response to all sucrose/water stimulations) (Scheiner et al. 2003).

In Experiment 1, we compared the sucrose responsiveness of five castes performing different tasks: gynes, males, nurses, inactive workers, and foragers. Gynes and males were collected from three colonies 2 wk after they showed activity in the foraging arena; minor workers were collected from two different colonies and assigned to one of three behavioral castes (marked with different color paint) after 2 wk of behavioral observations ( $1 \mathrm{~h}$, twice a day): foragers, if they collected food or water; nurses, if they were involved in brood care, or "inactive," if they displayed reduced locomotor activity and a distended (full) abdomen at the beginning of sucrose deprivation. The SRS of each caste was then determined (for workers, assays were performed blind with respect to individual behavioral task).

In Experiment 2, nurses and foragers were tested for their SRS and then subjected to a differential conditioning procedure with two odors, a rewarding one and a nonrewarding one. Nurses and foragers were collected from four colonies and their SRTs were determined. Individuals that responded to the highest sucrose concentration assay (30\%) were used $1 \mathrm{~h}$ later for differential conditioning experiments in which the unconditioned stimulus (US) was 30\% sucrose solution. We trained ants to respond with MaLER to a CS+ odor paired with the US and not to a CS - odor that was not paired with the US. Octanal and hex- anol (floral scents, Sigma Aldrich) were used as CS + and CS - in a balanced way. Six microliters of pure odorant were applied onto a piece of filter paper that was inserted in a plastic 10-mL syringe. Ants responding to the first presentation of the CS+ or the CSwere discarded. The acquisition phase consisted of 12 trials (six $\mathrm{CS}+$ presentations and six CS - presentations in pseudo-random order, i.e., no more than two trials of the same CS type were allowed [Guerrieri and d'Ettorre 2010]). Each trial lasted $1 \mathrm{~min}$. In CS + trials, odor stimulation lasted $5 \mathrm{sec}$ and preceded sucrose stimulation by $3 \mathrm{sec}$, which also lasted $5 \mathrm{sec}$. In CS - trials, only the 5 -sec odorant stimulation was delivered. In both cases, $25 \mathrm{sec}$ and 30 sec elapsed before and after stimulus delivery, respectively. Intertrial interval was $10 \mathrm{~min}$. An air extractor was placed behind the ant to remove undesired odorant stimulations. Only individuals that responded at least five times to the US were included in the statistical analyses. Individual acquisition scores to $\mathrm{CS}+(\mathrm{AS}+)$ and CS - (AS -) were calculated as the sum of an ant's conditioned responses (CR) to CS+ and CS - , respectively. These scores vary between 0 (no CR to $\mathrm{CS}+/ \mathrm{CS}-$ ) and 5 (CR to $\mathrm{CS}+/ \mathrm{CS}-$ in trials $2-6$ ).

Statistical analyses were performed with R environment (version 2.15.0, http://www.R-project.org/). Two-tailed KruskalWallis tests were used to test variation in SRS and WRS between worker and sexual castes (package pgirmess; see CRAN.R-project. org/package=pgirmess). Multiple Wilcoxon-Mann-Whitney rank sum tests were applied for pairwise comparisons between castes (with sequential Bonferroni corrections) and for testing differences in SRS, WRS, AS+, and AS - between nurses and foragers. Spearman rank correlation test was used to study correlations between SRS and AS+ (Rcorr function, package Hmisc; http:// CRAN.R-project.org $/$ package=Hmisc). For further details about statistics see Supplemental Material.

In Experiment 1, sucrose and water responsiveness scores (SRS and WRS, respectively) differed significantly between castes (SRS, Kruskal-Wallis, $\chi^{2}=69.58, \mathrm{df}=4, P<0.001 \quad$ [Fig. 1A]; WRS, $\chi^{2}=57.21, \mathrm{df}=4, P<0.001$ [Fig. 1B]; see Supplemental Fig. S2 for sucrose and water responsiveness curves). Although foragers and males exhibited higher SRS and WRS values, inactive workers and gynes showed lower SRS and WRS values. Nurses showed intermediate SRS values and WRS values similar to those of foragers (Table 1 ).

In Experiment 2, we quantified sucrose responsiveness of nurses and foragers (Supplemental Fig. S3) and kept only those ants $(83.87 \%$ and $50.81 \%$, respectively, of foragers and nurses
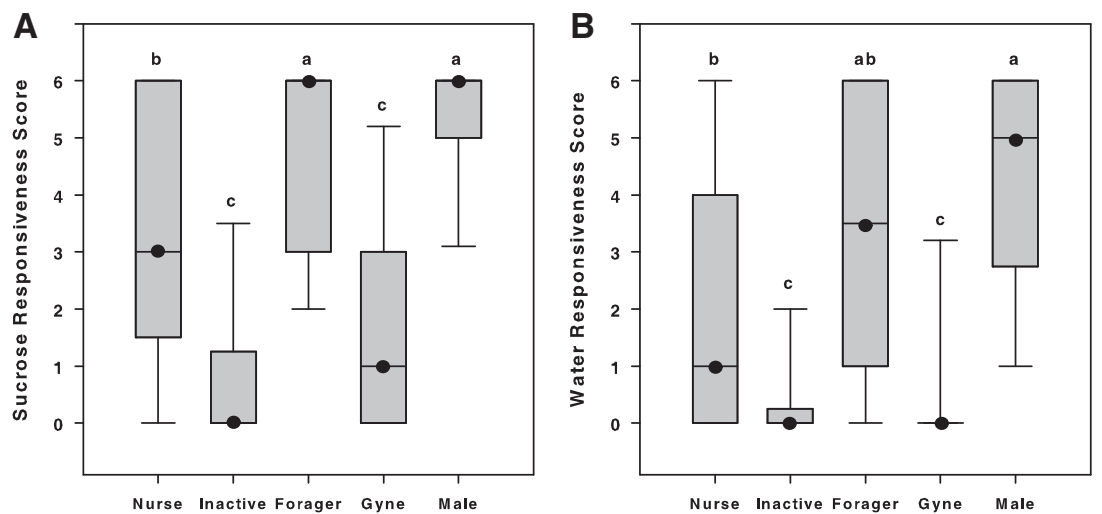

Figure 1. Sucrose and water responsiveness scores of the five castes. $(A)$ Box plots of sucrose responsiveness score of nurses $(n=37)$, inactive workers $(n=34)$, foragers $(n=44)$, gynes $(n=23)$, and males $(n=26)$. (B) Boxplots of water responsiveness scores of the same individuals. SRS and WRS vary between 0 (no response to sucrose/water stimulation) and 6 (response to all six stimulations). Boxes show median (line and dot), 1st and 3rd quartiles, 5th and 95th percentiles (whiskers). Groups that are statistically different have different letters. 
Table 1. Comparison of SRS and WRS between castes

\begin{tabular}{|c|c|c|c|}
\hline Caste 1 & Caste 2 & $\begin{array}{c}\text { SRS (adjusted } \\
P \text {-value) }\end{array}$ & $\begin{array}{l}\text { WRS (adjusted } \\
\text { P-value) }\end{array}$ \\
\hline \multirow[t]{4}{*}{ Foragers } & Nurses & $<0.05$ & 0.052 \\
\hline & $\begin{array}{l}\text { Inactive } \\
\text { workers }\end{array}$ & $<0.001$ & $<0.001$ \\
\hline & Gynes & $<0.001$ & $<0.001$ \\
\hline & Males & NS & NS \\
\hline \multirow[t]{3}{*}{ Nurses } & $\begin{array}{l}\text { Inactive } \\
\text { workers }\end{array}$ & $<0.001$ & $<0.05$ \\
\hline & Gynes & $<0.01$ & $<0.05$ \\
\hline & Males & $<0.01$ & $<0.001$ \\
\hline \multirow{3}{*}{$\begin{array}{l}\text { Inactive } \\
\text { workers } \\
\text { Gynes }\end{array}$} & Gynes & NS & \\
\hline & Males & $<0.001$ & $<0.001$ \\
\hline & Males & $<0.001$ & $<0.001$ \\
\hline
\end{tabular}

Adjusted $P$-values correspond to pairwise comparisons of scores between each caste (sequential Bonferroni corrections after multiple WilcoxonMann-Whitney rank sum tests). (NS) not significant.

assayed) that responded to the highest sucrose concentration (30\%), used as US in the subsequent conditioning procedure. As in the previous experiment, SRS values were significantly higher in foragers than in nurses, but WRS values were not statistically different (SRS, Wilcoxon-Mann-Whitney rank sum test, $W=$ 890.5, $P<0.05$; WRS, $W=1028.5, P=0.25$ ).

Both castes learned the discrimination between rewarded and unrewarded odors (see Supplemental Fig. S4 for learning curves), but foragers learned the olfactory discrimination better than nurses. Indeed, foragers exhibited higher AS+ values than nurses $(W=888, P<0.05$ ) (Fig. 2$)$, although AS - values did not differ $(W=1077.5, P=0.31)$. Thus, AS+ values are a reliable indicator of individual learning success. AS + values were positively correlated with SRS values for nurses $(n=35, \mathrm{rs}=0.62, P<$ $0.0001)$ and approached significance for foragers $(n=68$, rs $=$ $0.23, P=0.055)$. AS - values also correlated positively with SRS values both for nurses $(n=35, \mathrm{rs}=0.54, P<0.0001)$ and foragers ( $n=68, \mathrm{rs}=0.28, P=0.05$ ), thus indicating that the excitatory strength from the CS+ generalized in part to the CS - .

Our results show for the first time that different castes of an ant species exhibit a significant variation in their sucrose responsiveness, which is ecologically relevant since these ants feed on extra-floral nectaries. This inter-caste variation in sucrose response scores (SRS) found in C. aethiops is in line with the response threshold model of division of labor (Beshers and Fewell 2001): Foragers, for instance, proved to be highly sensitive both to sucrose (high SRS) and to water (high WRS). Higher WRS and SRS endow ants with the capacity to collect water and to sample food sources of variable quality, thus increasing information gathering about potential food sources. Inactive workers, in contrast, exhibited low WRS and SRS as they did not practically respond to water and responded only to the highest sucrose concentrations. This high selectivity for sucrose is adaptive in a scenario in which inactive workers serve as sucrose storers for the colony. The low SRS found in these ants could relate to the fact that crop filling induces a decrease in sucrose responsiveness (Falibene and Josens 2012). Nurses, which are younger than foragers and inactive workers (Hölldobler and Wilson
1990), responded to intermediate sucrose concentrations. They could, therefore, modulate their responsiveness and specialize in different tasks as they age. Gynes responded only to highest sucrose concentrations probably because they need to store energy for solitary colony founding and egg laying. By contrast, males, which die quickly after swarming and do not need to store energy, may afford high responsiveness to water and low sucrose concentrations. This scenario thus proposes that both sucrose and water responsiveness are adaptive traits related to the specific biological constraints of each caste. Variations in water responsiveness would reflect such biological differences and a general state of responsiveness to appetitive stimuli rather than being the mere result of sucrose sensitization.

The superior learning performance of foragers compared to that of nurses is relevant for quickly acquiring local environmental cues (e.g., olfactory ones) predicting food, thus increasing foraging efficiency. Their higher level of acquisition likely results from their higher responsiveness to sucrose reward (i.e., their high SRS), similarly to honeybees, where pollen foragers show better acquisition performances than nectar foragers due to their higher responsiveness to sucrose (Scheiner et al. 2005).

The picture emerging from these experiments is one in which castes within an ant colony differ in terms of their responsiveness to food reward and therefore in their learning capabilities in conditioning experiments in which this food reward is used as US. Although learning was only evaluated in foragers and nurses, the sucrose scores found for the other castes allow predicting their learning success. Males, like foragers, had higher SRS and are thus expected to have a learning success as high as that of foragers. Inactive workers and gynes, which showed SRS lower than those of nurses, should be the less efficient learners.

In conclusion, $C$. aethiops exhibit interindividual variability in sucrose and water responsiveness, thereby supporting the response threshold model of division of labor. Differences in appetitive learning are thus likely mediated by sucrose responsiveness and relate to behavioral tasks.

\section{Acknowledgments}

We thank A. Dussutour and S. Teseo for comments on previous versions of the manuscript and $H$. Rödel for help with statistical analyses. M.G. was supported by the Institut Universitaire de France, the French Research Council (CNRS) and the University Paul Sabatier and P.dE. by a Marie Curie Reintegration Grant.
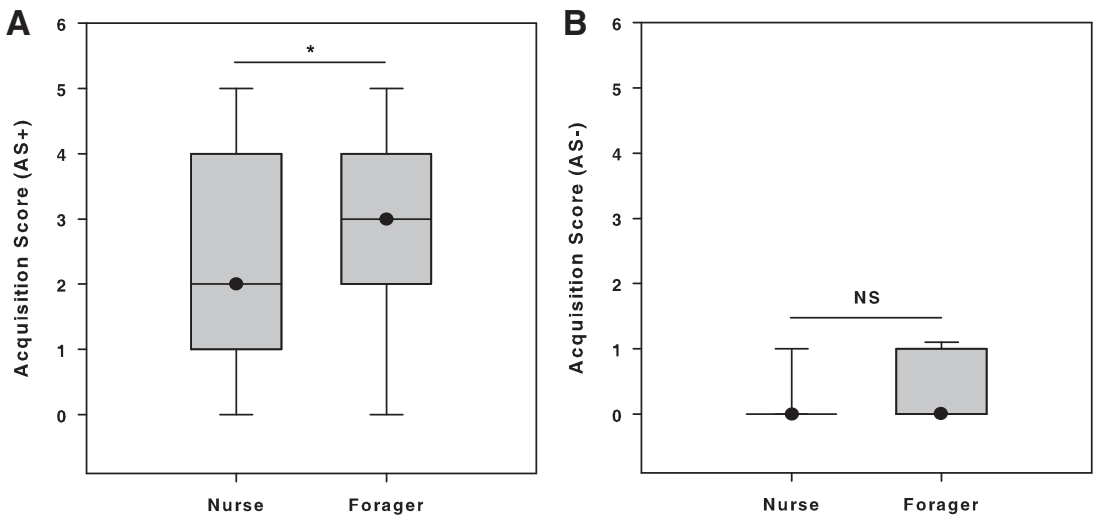

Figure 2. Learning success of nurses and foragers. Box plots of acquisition score to $(A) \mathrm{CS}+(\mathrm{AS}+)$ and $(B) C S-(A S-)$ of nurses $(n=35)$ and foragers $(n=68)$. AS + and AS - vary between 0 (no response to $C S+$ and $C S-$, respectively, during all successive trials) and 5 (positive responses to $C S+$ and CS - , respectively, after the first trial). Boxes show median (line and dot), 1 st and 3rd quartiles, 5th and 95th percentiles (whiskers). $\left(^{*}\right) P<0.05$. 
This work was supported by the CNRS research network GDR 2822 Ethologie.

\section{References}

Avarguès-Weber A, Deisig N, Giurfa M. 2011. Visual cognition in social insects. Annu Rev Entomol 56: 423-443.

Beshers SN, Fewell JH. 2001. Models of division of labor in social insects. Annu Rev Entomol 46: 413-440.

Bonabeau E, Theraulaz G, Deneubourg JL. 1996. Quantitative study of the fixed threshold model for the regulation of division of labour in insect societies. Proc R Soc B 263: 1565-1569.

Dupuy F, Sandoz J-C, Giurfa M, Josens R. 2006. Individual olfactory learning in Camponotus ants. Anim Behav 72: 1081-1091.

Falibene A, Josens R. 2012. Sucrose acceptance threshold: A way to measure sugar perception in ants. Insect Soc 59: 75-80.

Falibene A, de Figueiredo Gontijo A, Josens R. 2009. Sucking pump activity in feeding behavior regulation in carpenter ants. J Insect Physiol 55: 518-524.

Giurfa M. 2007. Behavioral and neural analysis of associative learning in the honeybee: A taste from the magic well. J Comp Physiol A 193: 801-824.

Giurfa M. 2013. Cognition with few neurons: Higher-order learning in insects. Trends Neurosci 363: 285-294.

Guerrieri FJ, d'Ettorre P. 2010. Associative learning in ants: Conditioning of the maxilla-labium extension response in Camponotus aethiops. J Insect Physiol 56: 88-92.

Guerrieri FJ, d'Ettorre P, Devaud J-M, Giurfa M. 2011. Long-term olfactory memories are stabilized via protein synthesis in Camponotus fellah ants. J Exp Biol 214: 3300-3304.

Hölldobler B, Wilson EO. 1990. The ants. Springer-Verlag, Berlin.

Josens R, Farina WM, Roces F. 1998. Nectar feeding by the ant Camponotus mus: Intake rate and crop filling as a function of sucrose concentration. J Insect Physiol 44: 579-585.
Page RE Jr, Erber J, Fondrk MK. 1998. The effect of genotype on response thresholds to sucrose and foraging behavior of honey bees (Apis mellifera L.). J Comp Physiol A 182: 489-500.

Pankiw T, Page RE Jr. 1999. The effect of genotype, age, sex, and caste on response thresholds to sucrose and foraging behavior of honey bees (Apis mellifera L.). J Comp Physiol A 185: 207-213.

Pankiw T, Waddington K, Page RE Jr. 2001. Modulation of sucrose response thresholds in honey bees (Apis mellifera L.): Influence of genotype, feeding, and foraging experience. J Comp Physiol A 187: 293-301.

Robinson GE. 1992. Regulation of division of labor in insect societies. Annu Rev Entomol 37: 637-665.

Scheiner R, Arnold G. 2010. Effects of patriline on gustatory responsiveness and olfactory learning in honey bees. Apidologie 41: 29-37.

Scheiner R, Erber J, Page RE Jr. 1999. Tactile learning and the individual evaluation of the reward in honey bees (Apis mellifera L.). J Comp Physiol A 185: $1-10$.

Scheiner R, Page RE Jr, Erber J. 2001a. Responsiveness to sucrose affects tactile and olfactory learning in preforaging honey bees of two genetic strains. Behav Brain Res 120: 67-73.

Scheiner R, Page RE Jr, Erber J. 2001b. The effects of genotype, foraging role, and sucrose responsiveness on the tactile learning performance of honey bees (Apis mellifera L.). Neurobiol Learn Mem 76: $138-150$.

Scheiner R, Barnert M, Erber J. 2003. Variation in water and sucrose responsiveness during the foraging season affects proboscis extension learning in honey bees. Apidologie 34: 67-72.

Scheiner R, Kuritz-Kaiser A, Menzel R, Erber J. 2005. Sensory responsiveness and the effects of equal subjective rewards on tactile learning and memory of honeybees. Learn Mem 12: 626-635.

Schilman PE. 2011. Trail-laying behavior as a function of resource quality in the ant Camponotus rufipes. Psyche. doi: 10.1155/2011/139385.

Wilson EO. 1971. The insect societies. Harvard University Press, Cambridge, MA.

Received April 15, 2013; accepted in revised form June 4, 2013. 


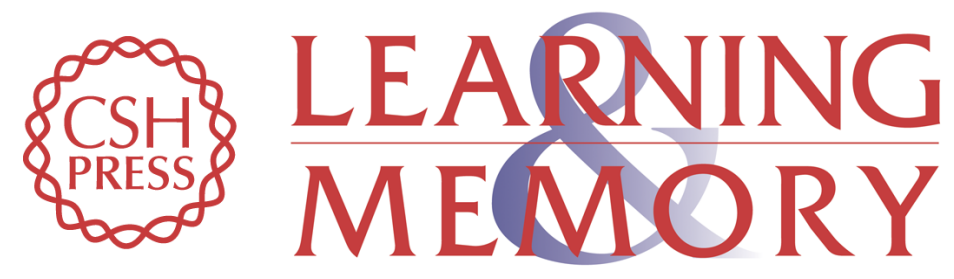

\section{Sucrose responsiveness, learning success, and task specialization in ants}

Margot Perez, Uther Rolland, Martin Giurfa, et al.

Learn. Mem. 2013, 20:

Access the most recent version at doi:10.1101/Im.031427.113

\section{Supplemental http://learnmem.cshlp.org/content/suppl/2013/07/08/20.8.417.DC1 Material}

References This article cites 22 articles, 2 of which can be accessed free at: http://learnmem.cshlp.org/content/20/8/417.full.html\#ref-list-1

Creative This article is distributed exclusively by Cold Spring Harbor Laboratory Press for the Commons first 12 months after the full-issue publication date (see

License http://learnmem.cshlp.org/site/misc/terms.xhtml). After 12 months, it is available under a Creative Commons License (Attribution-NonCommercial 3.0 Unported), as described at http://creativecommons.org/licenses/by-nc/3.0/.

Email Alerting Receive free email alerts when new articles cite this article - sign up in the box at the Service top right corner of the article or click here. 